\title{
Study on patient dosimetry and image quality in digital mammography
}

\author{
Aline Carvalho da Silva Xavier ${ }^{1}$, Marcos Ely Almeida Andrade ${ }^{1,2 *}$, Beatriz Villa-Chan Cantalupo Pinto ${ }^{1}$, \\ Vinícius Saito Monteiro de Barros ${ }^{1}$, Richard Kramer ${ }^{1}$, Helen Jamil Khoury ${ }^{1}$ \\ ${ }^{1}$ Departament of Nuclear Energy, Federal University of Pernambuco, Recife, PE, Brazil. \\ ${ }^{2}$ Post-graduate Interdisciplinary Core, Integrated Faculty of Pernambuco, Recife, PE, Brazil.
}

\begin{abstract}
Introduction: Digital mammography present many advantages in comparison to conventional mammography, such as high dynamic range and the post-processing of acquired images. One problem is that protocols may not be optimized, resulting in higher absorbed doses to patients. The objective of this work is to evaluate image quality and to estimate mean glandular doses (MGD) in patients submitted to mammography examinations with three digital systems and one screen-film system in Recife, Brazil. Methods: To estimate the MGD, the parameters used to acquire images of 5475 patients, with ages between 40 and 64 years and compressed breasts between 2 and $9 \mathrm{~cm}$, were registered. The MGD was calculated by multiplying the incident air kerma with conversion coefficients depending on the anode/filter, breast glandularity and half-value layer. The image quality evaluation of the digital systems was made using objective and subjective European criteria. Results: The results showed MGDs in the range of 0.4-10.3 mGy and the higher values were observed with digital systems. It was also observed that in the digital systems the use of compression force is not adequate and the irradiation parameters are not optimized. The images failed to reproduce the pectoral muscle and the contrast-to-noise ratio was not adequate for one system, indicating the need to improve the patient's positioning and the exposure parameters. Conclusion: It can be concluded that the use of non-optimized irradiation parameters is causing the higher doses with digital systems, highlighting the insufficient compression force.
\end{abstract}

Keywords Mammography, Mean glandular dose, Image quality, Digital radiography.

\section{Introduction}

Breast cancer is the second most frequent cancer in the world and the one with the highest incidence among women. Mammography and clinical examinations are the most efficient methods to detect breast cancer in the early stages of development (Instituto..., 2014).

Digital mammography systems, which can be computed radiography (CR) or direct digital radiography (DR), present many advantages in comparison to conventional mammography (screen-film systems), such as high dynamic range and the possibility of post-processing of the acquired images (Körner et al., 2007). The CR system can be used in conventional X-ray equipment by changing

(1) This is an Open Access article distributed under the terms of the Creative Commons Attribution License, which permits unrestricted use, distribution, and reproduction in any medium, provided the original work is properly cited.

How to cite this article: Xavier ACS, Andrade MEA, Pinto BVCC, Barros VSM, Kramer R, Khoury HJ. Study on patient dosimetry and image quality in digital mammography. Res Biomed Eng. 2017; 33(2):138-143. DOI: 10.1590/2446-4740.02117

*Corresponding author: Departamento de Energia Nuclear, Universidade Federal de Pernambuco - UFPE, Av. Prof. Luiz Freire, 1000, Cidade Universitária, CEP 50740-540, Recife, PE, Brazil. E-mail: marcos.ely@gmail.com

Received: 25 April 2017 / Accepted: 22 June 2017 the cassette to a phosphor image plate and the film processor to a CR reader. However, using DR systems requires the replacement of the entire mammography equipment because of the flat panel detector.

Digital detectors show a linear response over a wide range of radiation intensities, and for this reason, it is difficult to observe the effect of the high radiation doses in the image, differently of the conventional mammography, where the optical density of the film saturate with high doses. For this reason, it is important to estimate the glandular dose received by the patients and to evaluate the irradiation parameters to warranty a quality image for the diagnosis.

The objective of this work is to evaluate the image quality and to estimate mean glandular doses (MGD) in patients who were submitted to mammography examinations with three digital systems and one screen-film system in Recife, Brazil.

\section{Methods}

\section{Mammography equipment}

The study was performed in four clinics, located in the cities of Recife, northeast region of Brazil. Table 1 shows the characteristics of the mammography equipment per clinic. 
Table 1. Main characteristics of the equipment used in the four clinics were the study of performed.

\begin{tabular}{ccccc}
\hline & Clinic A & Clinic B & Clinic C & Clinic D \\
\hline Manufacturer, model & Siemens, Mammomat & Siemens, Mammomal & Hologic, Lorad Selenia & Hologic, Lorad Selenia \\
& 3000 Nova & 1000 & & \\
Image detector & CR - BaFBr:Eu & Kodak Screen FILM & DR1 a-Se / TFT & DR2 a-Se / TFT \\
Anode & Mo; $\mathrm{W}$ & Mo & Mo & Mo \\
Filter & Mo; Rh & Mo; Rh & Mo; Rh & Mo; Rh \\
\hline
\end{tabular}

Prior to measurement, performance checks were made with all four systems by the Laboratório de Metrologia das Radiações Ionizantes (LMRI) observing the quality criteria defined by the Brazilian legislation (Brasil, 1998, 2013).

Tube output was measured for several combinations of tube voltage $(\mathrm{kVp})$ and anode/filter using a calibrated ionization chamber (Keithley 96035B) positioned at $45 \mathrm{~mm}$ from the breast support.

\section{Dose calculation}

To estimate the mean glandular dose $(M G D)$, the irradiation parameters used to acquire the mammographic images of 5475 patients with ages between 40 and 64 years, with compressed breast between 2 and $9 \mathrm{~cm}$, were registered. Only routine acquisitions were considered.

The $M G D$ calculations used the method described by Dance et al. (2000), i.e. multiplying $K_{a, i}$ with conversion coefficients depending on the anode/filter combination, breast glandularity and half-value layer, according to the following equation:

$\mathrm{MGD}=$ s.g.c. $\mathrm{K}_{\mathrm{a}, \mathrm{i}}$

Values of $g$ are provided in a table depending on the $H V L$ (half-value layer) and the compressed breast thickness. $s$ depends on the anode/filter combination, and $c$ depends on the breast glandularity, the compressed breast thickness and the HVL. The breast glandularity depends on the breast thickness and the patient's age. The coefficients $(s, g$, and $c$ ) are found in tables published by Dance et al. (2000). This method is only valid to calculate MGDs for patients with ages between 40 and 64 years.

The value of Incident air kerma $\left(K_{a, i}\right)$ was estimated using the following equation:

$\mathrm{K}_{\mathrm{a}, \mathrm{i}}=\mathrm{R}_{\mathrm{i}} \cdot \mathrm{Q} \cdot\left(\frac{100 \mathrm{~cm}}{\mathrm{FSD}}\right)^{2}$

where $Q$ is the current-time product (mAs) and $R_{\mathrm{i}}$ is the tube output (in $\mathrm{mGy} / \mathrm{mAs}$ at $1 \mathrm{~m}$ ) corresponding to the voltage used to do the mammography, and FSD is the focus-to-skin distance.

\section{Image quality}

The image quality evaluation of the digital systems was made using objective and subjective criteria. The objective tests were performed based on the Quality Assurance Programme for Digital Mammography (International..., 2011).

The contrast-to-noise ratio (CNR) was measured acquiring two images: one of a disk made of polymethyl-methacrylate (PMMA) with $1 \times 25 \mathrm{~mm}$ (thickness $\mathrm{x}$ diameter) over $45 \mathrm{~mm}$ of PMMA; and a second image of a $0.2 \times 10 \mathrm{~mm}$ (thickness $\mathrm{x}$ width) aluminium square over $45 \mathrm{~mm}$ of PMMA. Two more images were acquired, by changing the PMMA's thickness (20 and $70 \mathrm{~mm}$ ). Spacers were then used in order to achieve other thicknesses $(53$ and $90 \mathrm{~mm}$ ). All acquisitions were performed using the automatic exposure mode or with equivalent parameters to routine mammography examinations. Figure 1 (image on the left) shows the positioning of the PMMA and contrast object for the CNR evaluations. The images acquired were analyzed using the software ImageJ. The CNR was calculated using the pixel values (and standard deviation) measured in and outside the contrast object.

The modulation transfer function (MTF) was measured using a test object (Figure 1 - right) over $45 \mathrm{~mm}$ of PMMA with the same parameters used for the CNR evaluation. Analysis was performed using the software QuickQC with the non-processed images of CR and DR2 and processed images of DR1.

The evaluations of the images, according to clinical criteria, were performed by three radiologists using the image quality parameters recommended by CEC (Commission..., 1996). 50 images were analysed at each CR or DR system.

\section{Results}

\section{Patients' characteristics and irradiation parameters}

$M G D$ was estimated for 5475 mammographic examinations. Breasts with silicon implants were not considered. The number of exams for each system was: 476 with the screen-film system; 366 with the CR system; 1213 with the DR1; and 3420 with the DR2. Table 2 

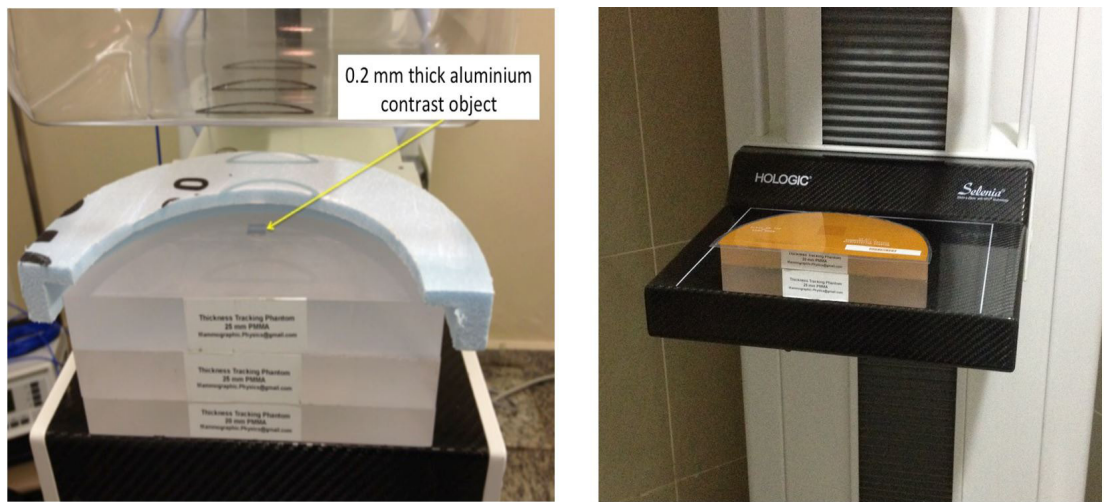

Figure 1. Experimental arrangement for image quality evaluations: CNR (left); and MTF (right).

Table 2. Mean and interval values of patients' characteristics and irradiation parameters.

\begin{tabular}{ccccccc}
\hline \multirow{2}{*}{ System* } & Values & $\begin{array}{c}\text { Patient age } \\
\text { (years) }\end{array}$ & $\begin{array}{c}\text { Compressed } \\
\text { breast } \\
\text { thickness }(\mathbf{c m})\end{array}$ & $\begin{array}{c}\text { Compression } \\
\text { force (N) }\end{array}$ & $\begin{array}{c}\text { Tube voltage } \\
\text { (kVp) }\end{array}$ & $\begin{array}{c}\text { Current-time } \\
\text { product (mAs) }\end{array}$ \\
\hline \multirow{2}{*}{ SF } & Average & $51.7 \pm 6.3$ & $4.8 \pm 1.1$ & $239 \pm 41$ & $26.0 \pm 1.5$ & $131 \pm 34$ \\
& Min-Max & $40-64$ & $2.0-8.9$ & $93-350$ & $24-31$ & $34-193$ \\
\hline \multirow{2}{*}{$\mathrm{CR}$} & Average & $51.7 \pm 7.4$ & $6.7 \pm 1.3$ & $\mathrm{NI} *$ & $30.2 \pm 1.2$ & $134 \pm 58$ \\
& Min-Max & $40-64$ & $2.5-9.0$ & $\mathrm{NI} * *$ & $27-31$ & $22-447$ \\
\hline \multirow{2}{*}{ DR1 } & Average & $50.7 \pm 6.1$ & $6.0 \pm 1.0$ & $80 \pm 21$ & $30.4 \pm 1.8$ & $89 \pm 25$ \\
& Min-Max & $40-64$ & $2.5-9.0$ & $39-173$ & $24-34$ & $48-311$ \\
\hline \multirow{2}{*}{ DR2 } & Average & $50.7 \pm 6.9$ & $6.1 \pm 1.2$ & $85 \pm 21$ & $30.4 \pm 1.9$ & $125 \pm 33$ \\
& Min-Max & $40-64$ & $2.2-9.0$ & $44-167$ & $24-34$ & $53-304$ \\
\hline
\end{tabular}

*SF: screen-film system; CR: computerized radiography; DR: direct digital radiography; **The compression force was not registered by this system for each examination.

shows the patient characteristics and the irradiation parameters for the registered examinations.

\section{Mean glandular dose analysis}

Figure 2 presents mean glandular doses as a box \& whiskers plot calculated for compressed breasts with thickness ranging from 2 to $9 \mathrm{~cm}$, showing the highest MGDs for the CR system.

\section{Image quality evaluation}

The CNRs are presented in Tables 3 for the PMMA disc and in the same table, in parenthesis, for the aluminium square, where $\mathrm{A}$ means adequate and NA means not adequate within the limits proposed by IAEA (International..., 2011). It can be observed that the CNR decreases with the increase of PMMA thickness (except for the CR system with $70 \mathrm{~mm}$ ), with the CR system showing the highest contrast-to-noise ratios.

Table 4 presents the results of the MTF analysis for the digital systems. The DR2 system shows MTF values lower than the IAEA (International..., 2011) limits. It has to be noted that the images obtained for the DR2 and CR systems were analyzed without digital processing,

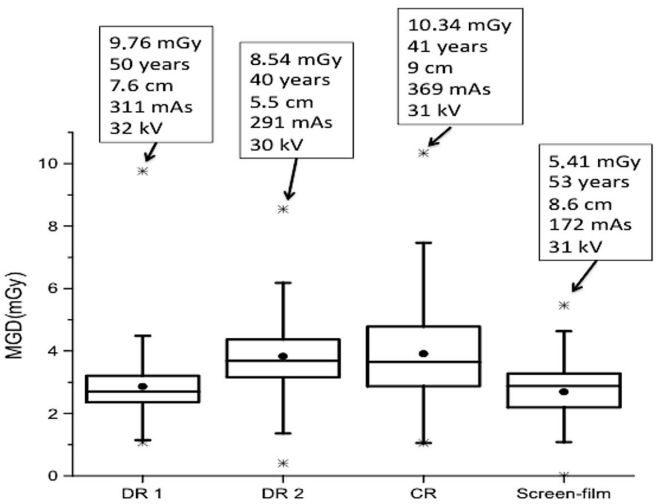

Figure 2. Mean glandular dose estimated for compressed breasts ranging from 2 to $9 \mathrm{~cm}$ for all evaluated mammography systems, with the description of the outlier values. CR: computerized radiography; DR: direct digital radiography.

while for the DR1 system only post-processed images were available.

The results of the image quality evaluation using the clinical criteria by CEC (Commission..., 1996) are presented in Table 5 for cranio-caudal projection $(\mathrm{CC})$ and 
Table 3. CNR for the three digital mammography systems for each thickness of PMMA and compared to reference. Contrast object: $1 \mathrm{~mm}$ PMMA disc (and $0.2 \mathrm{~mm}$ aluminium square).

\begin{tabular}{|c|c|c|c|c|}
\hline PMMA thickness & Equipment & CNR measured & CNR reference & Conclusion* \\
\hline \multirow{3}{*}{$20 \mathrm{~mm}$} & $\mathrm{CR}$ & $7.21(15.73)$ & $3.80(9.50)$ & $\mathrm{A}(\mathrm{A})$ \\
\hline & DR1 & $2.88(11.54)$ & $1.50(4.80)$ & $\mathrm{A}(\mathrm{A})$ \\
\hline & DR2 & $6.14(15.07)$ & $1.50(4.80)$ & $\mathrm{A}(\mathrm{A})$ \\
\hline \multirow{3}{*}{$45 \mathrm{~mm}$} & $\mathrm{CR}$ & $3.31(12.20)$ & $3.30(8.50)$ & $\mathrm{A}(\mathrm{A})$ \\
\hline & DR1 & $1.85(6.95)$ & $1.30(4.30)$ & $\mathrm{A}(\mathrm{A})$ \\
\hline & DR2 & $3.42(8.69)$ & $1.30(4.30)$ & $\mathrm{A}(\mathrm{A})$ \\
\hline \multirow{3}{*}{$70 \mathrm{~mm}$} & CR & $4.67(2.29)$ & $2.80(7.50)$ & $\mathrm{A}(\mathrm{NA})$ \\
\hline & DR1 & $0.22(3.61)$ & $1.00(3.80)$ & NA (NA) \\
\hline & DR2 & $1.86(4.42)$ & $1.00(3.80)$ & $\mathrm{A}(\mathrm{A})$ \\
\hline
\end{tabular}

CR: computerized radiography; DR: direct digital radiography. *A: adequate; NA: not adequate.

Table 4. MTF for the three evaluated digital mammography systems.

\begin{tabular}{lrrr}
\hline \multicolumn{1}{c}{ Parameter } & CR & DR1 & DR2 \\
\hline Tube voltage (kV) & 29 & 31 & 32 \\
Current-time product (mAs) & 93.3 & 51.7 & 70.3 \\
MTF 20\% (Horizontal) & 3.4 & 12.0 & 8.0 \\
MTF 20\% (Vertical) & 3.6 & 13.0 & 8.0 \\
Reference 20\%* & 3.0 & 9.0 & 9.0 \\
MTF 50\% (Horizontal) & 1.6 & 7.1 & 4.0 \\
MTF 50\% (Vertical) & 1.9 & 8.3 & 4.0 \\
Reference 50\%* & 1.5 & 6.5 & 6.5 \\
\hline
\end{tabular}

CR: computerized radiography; DR: direct digital radiography. *IAEA (International..., 2011)

mid-lateral oblique projection (MLO). Pectoral muscle and nipple visualizations were the criteria with the worst results in cranio-caudal projections, while in mid-lateral oblique projections the visualization of infra-mammary angle and the nipple in full profile were the ones with poor results.

\section{Discussion}

It can be observed in Table 2 that most of the compression forces used in these examinations are not adequate to the Brazilian legislation (Brasil, 1998). The recommended force ranges from 108 to $176 \mathrm{~N}$. Most the examinations performed with the screen-film system used heavy compressions, while the examinations with the CR and DR systems used light compressions.

While the use of high compression forces increases the discomfort for the patient, the use of low forces results in thicker compressed breasts. This may cause overlapping of important anatomical structures and results in examinations with high tube voltages.

It can also be observed in the data presented in Table 2 that the digital systems used a larger current-time product (mAs) range compared to the screen-film system. This occurs because the use of high mAs values in the
SF system causes optical density saturation, deteriorating the image contrast. In CR or DR systems, which have detectors with a large dynamic range, the contrast is always adequate and the signal-to-noise ratio improves with higher radiation intensity. This suggests that the automatic exposure control (AEC) could be optimized to provide lower values of the current-time product without compromising the image quality.

Regarding MGD, it can be seen from the data in Figure 2 that doses were higher for the CR system, which was also observed by others (Yaffe et al., 2013). The highest MGD value was $10.34 \mathrm{mGy}$, for the CR system (breast with $9 \mathrm{~cm}$ of thickness, performed with $31 \mathrm{kV}$ and $369 \mathrm{mAs}$ ). High MGD values were also found for both DR systems. These data indicate the need for optimization and dose reduction in digital equipment. Yaffe et al. (2013) estimated that women receiving a mean absorbed dose of $3.7 \mathrm{mGy}$ in both breasts, annually since 40 years-old, have a cancer incidence risk of 86 cases in 100,000 exposed patients.

The DR2 system presented a high MGD value, when compared to the SF and DR1 systems. One possible cause is the use of insufficient compression force. According to Chida et al. (2009), the use of insufficient compression can increase the MGD in 20\% without improving the image quality.

Table 6 compares the results obtained in this work with others (all using the method described by Dance et al. to estimate the MGD). The MGDs estimated in this work were higher than MGDs published by others, although the values found in the literature cover a large range.

The examinations performed with the DR1 system cause lower glandular doses compared to the DR2 equipment. On the other hand, for breasts thicker than $45 \mathrm{~mm}$, DR1 has a CNR below the limit. This highlights that adjustments should be made in the automatic exposure control of both systems: in the DR2, the exposure 
Table 5. Approval rate using the European image quality criteria (Commission..., 1996) for cranio-caudal projection (CC) and medio-lateral oblique projection (MLO).

\begin{tabular}{|c|c|c|c|}
\hline Parameter & CR (\%) & DR1 (\%) & DR2 (\%) \\
\hline Visually sharp reproduction of pectoral muscle at image margin (CC) & 28 & 12 & 36 \\
\hline Visually sharp reproduction of retroglandular fat tissue (CC) & 84 & 88 & 88 \\
\hline Visually sharp reproduction of medial breast tissue (CC) & 100 & 100 & 100 \\
\hline Visually sharp reproduction of lateral glandular tissue (CC) & 100 & 100 & 100 \\
\hline No skinfolds seen $(\mathrm{CC})$ & 84 & 88 & 80 \\
\hline Symmetrical images of left and right breast (CC) & 92 & 96 & 88 \\
\hline Visualization of skin outline with bright light (CC) & 88 & 96 & 88 \\
\hline Reproduction of vascular structures seen through most dense parenchyma (CC) & 100 & 100 & 100 \\
\hline $\begin{array}{l}\text { Visually sharp reproduction of all vessels and fibrous strands and pectoral muscle margin } \\
\text { (absence of movement) (CC) }\end{array}$ & 24 & 12 & 32 \\
\hline $\begin{array}{l}\text { Visually sharp reproduction of skin structure (rosettes from pores) along the pectoralis } \\
\text { muscle (CC) }\end{array}$ & 20 & 12 & 28 \\
\hline Pectoral muscle at correct angle (MLO) & 84 & 92 & 96 \\
\hline Infra-mammary angle visualized (MLO) & 32 & 56 & 44 \\
\hline Visually sharp reproduction of cranio-lateral glandular tissue (MLO) & 100 & 100 & 100 \\
\hline Visually sharp reproduction of retroglandular fat tissue (MLO) & 92 & 96 & 92 \\
\hline Nipple in full profile, clear of overlying breast tissue and/or indicated by marker (MLO) & 36 & 52 & 40 \\
\hline No skinfolds seen (MLO) & 60 & 80 & 72 \\
\hline Symmetrical images of left and right breast (MLO) & 68 & 100 & 76 \\
\hline Visualization of skin outline with bright light (MLO) & 96 & 92 & 96 \\
\hline Reproduction of vascular structures seen through most dense parenchyma (MLO) & 96 & 100 & 96 \\
\hline
\end{tabular}

CR: computerized radiography; DR: direct digital radiography.

Table 6. Comparison of MGD values (in mGy) found in this work against other published in the literature.

\begin{tabular}{lcccccc}
\hline \multicolumn{1}{c}{ Authors } & Country & $\begin{array}{c}\text { Number of } \\
\text { patients }\end{array}$ & DR1 & DR2 & CR & SF \\
\hline This work & Brazil & 5475 & 2.86 & 3.83 & 3.91 & 2.70 \\
Hendrick et al. $(2010)^{1}$ & Canada & 49528 & 1.70 & 2.50 & 2.10 & 2.50 \\
Kawaguchi et al. $(2014)^{2}$ & Japan & 300 & 2.08 & 2.08 & - & - \\
Morán et al. $(2005)^{3}$ & Spain & 5034 & 1.88 & 1.88 & - & - \\
Young $(2002)^{4}$ & UK & 2296 & - & - & - & 2.37 \\
\hline
\end{tabular}

SF: screen-film system; CR: computerized radiography; DR: direct digital radiography. ${ }^{1}$ The mean breast thicknesses were: $5.6 \mathrm{~cm} ; 6.2 \mathrm{~cm} ; 5.3 \mathrm{~cm} ;$ and $5.1 \mathrm{~cm}$ (respectively); ${ }^{2}$ Mean breast thickness: $3.8 \mathrm{~cm} ;{ }^{3}$ Mean breast thickness: $5.2 \mathrm{~cm} ;{ }^{4}$ Mean breast thickness: $5.2 \mathrm{~cm}$.

parameters ( $\mathrm{kVp}$ and/or $\mathrm{mAs})$ could be reduced and in the DR1, the parameters could be increased.

As for the evaluation of the clinical quality criteria, it can be noted that most of the images fail to reproduce the pectoral muscle (and its associated criteria). According to Aguillar et al. (2009) the pectoral muscle can only be visualized in $30 \%$ of the images in the cranio-caudal projection due to the relaxation of the patient. This is also the recommended rate of Brazilian legislation (Brasil, 2013). The visualization of the pectoral muscle can be hampered by the use of inadequate compression or positioning errors (Sabino et al., 2014). These fails were confirmed in the evaluation of mid-lateral oblique projections, where the visualization of the infra-mammary angle and the nipple in full profile indicate positioning errors and can mask tumor masses and microcalcifications.

It can be concluded from this work that MGDs estimated for the digital systems were higher than international recommendations and higher than the corresponding screen-film data. The use of non-optimized irradiation parameters is the cause behind this result, highlighting the insufficient compression force. The contrast-to-noise ratios were lower than the international limits for dense breasts, making it difficult to visualize important structures. The clinical image quality results reflect the need for training for the technicians and technologists and the need to implement a quality assurance programme with optimization of the exposure parameters. 


\section{Acknowledgements}

The authors thank the Brazilian agencies CAPES and FACEPE for the financial support.

\section{References}

Aguillar V, Bauab S, Maranhão N. Mama: diagnóstico por imagem. Rio de Janeiro: Revinter; 2009.

Brasil. Ministério da Saúde. Portaria SVS/MS no 453, de 1 de junho de 1998. Aprova o Regulamento Técnico que estabelece as diretrizes básicas de proteção radiológica em radiodiagnóstico médico e odontológico, dispõe sobre o uso dos raios- $x$ diagnósticos em todo território nacional e dá outras providências. Diário Oficial da República Federativa do Brasil, Brasília, 1998.

Brasil. Ministério da Saúde. Portaria n ${ }^{\circ} 2.898$, de 28 de novembro de 2013. Atualiza o Programa Nacional de Qualidade em Mamografia (PNQM). Diário Oficial da República Federativa do Brasil. Brasília, 2013.

Chida K, Komatsu Y, Sai M, Nakagami A, Yamada T, Yamashita T, Mori I, Ishibashi T, Maruoka S, Zuguchi M. Reduced compression mammography to reduce breast pain. Clinical Imaging. 2009; 33(1):7-10. http://dx.doi.org/10.1016/j. clinimag.2008.06.025. PMid:19135922.

Commission of the European Communities. European guidelines on quality criteria for diagnostic radiographic images. Bruxelles: CEC; 1996.

Dance D, Skinner C, Young KC, Beckett JR, Kotre CJ. Additional factors for the estimation of mean glandular breast dose using the UK mammography dosimetry protocol. Physics in Medicine and Biology. 2000; 45(11):3225-40. http://dx.doi. org/10.1088/0031-9155/45/11/308. PMid:11098900.

Hendrick RE, Pisano ED, Averbukh A, Moran C, Berns EA, Yaffe MJ, Herman B, Acharyya S, Gatsonis C. Comparison of acquisition parameters and breast dose in digital mammography and screen-film mammography in the American College of Radiology Imaging Network Digital Mammographic Imaging
Screening Trial. AJR. American Journal of Roentgenology. 2010; 194(2):362-9. http://dx.doi.org/10.2214/AJR.08.2114. PMid:20093597.

Instituto Nacional do Câncer. Tipos de câncer: mama. Rio de Janeiro: INCA; 2014 [cited 2016 June 9]. Available from: http://www2.inca.gov.br/wps/wcm/connect/tiposdecancer/ site/home/mama

International Atomic Energy Agency. Human Health Series N17: Quality Assurance Programme for Digital Mammography. Viena: IAEA; 2011.

Kawaguchi A, Matsunaga Y, Otsuka T, Suzuki S. Patient investigation of average glandular dose and incident air kerma for digital mammography. Radiol Phys Tech. 2014; 7(1):102-8. http://dx.doi.org/10.1007/s12194-013-0239-9. PMid:24234736.

Körner M, Weber CH, Wirth S, Pfeifer KJ, Reiser MF, Treitl M. Advances in digital radiography: physical principles and system overview. Radiographics. 2007; 27(3):675-86. http:// dx.doi.org/10.1148/rg.273065075. PMid:17495286.

Morán P, Chevalier M, Ten JI, Fernández Soto JM, Vañó E. A survey of patient dose and clinical factors in a full-field digital mammography system. Radiation Protection Dosimetry. 2005; 114(1-3):375-9. http://dx.doi.org/10.1093/rpd/nch514 PMid:15933140.

Sabino SMS, Silva TB, Watanabe AH, Syrjänen K, Carvalho AL, Mauad EC. Implementation of a clinical quality control program in a mammography screening service of Brazil. Anticancer Research. 2014; 34(9):5057-65. PMid:25202091.

Yaffe MJ, Bloomquist AK, Hunter DM, Mawdsley GE, Chiarelli AM, Muradali D, Mainprize JG. Comparative performance of modern digital mammography systems in a large breast screening program. Medical Physics. 2013; 40(12):1-10. http:// dx.doi.org/10.1118/1.4829516. PMid:24320526.

Young KC. Radiation doses in the UK trial of breast screening in women aged 40-48 years. The British Journal of Radiology. 2002; 75(892):362-70. http://dx.doi.org/10.1259/bjr.75.892.750362. PMid:12000696. 